\title{
Preparation of epitaxial films of the transparent conductive oxide Al:ZnO by reactive high-pressure sputtering in $\mathrm{Ar} / \mathrm{O}_{2}$ mixtures
}

applications and materials science

\author{
M. Van Gompel ${ }^{*, 1}$, B. Conings ${ }^{1}$, K. L. Jiménez Monroy', J. D’Haen ${ }^{1,2}$, K. Gilissen ${ }^{1}$, M. D’Olieslaeger ${ }^{1,2}$, \\ M. K. Van Bael ${ }^{2,3}$, and P. Wagner ${ }^{1,2}$ \\ ${ }^{1}$ Institute for Materials Research (IMO), Material Physics, Hasselt University, Wetenschapspark 1, 3590 Diepenbeek, Belgium
${ }^{2}$ IMEC vzw, Division IMOMEC, Wetenschapspark 1, 3590 Diepenbeek, Belgium
${ }^{3}$ Institute for Materials Research (IMO), Inorganic and Physical Chemistry, Agoralaan, Building D, 3590 Diepenbeek, Belgium
}

Received 22 December 2012, revised 6 February 2013, accepted 7 February 2013

Published online 8 March 2013

Keywords DC sputtering, electrical transport properties, transparent conductive oxides, X-ray diffraction

*Corresponding author: e-mail matthias.vangompel@uhasselt.be, Phone: +32-11-268811, Fax: +32-11-268899

Transparent conductive metal oxides are interesting materials for various optoelectronic applications including solar cells and flat panel displays. This study focuses on the in situ deposition of aluminum-doped zinc oxide (AZO) thin layers on $c$-axis oriented sapphire substrates by dc sputtering and on the structural and electrical characterization. The films have a typical thickness of $90 \mathrm{~nm}$ and a roughness of $10 \mathrm{~nm}$ root mean square. An $\mathrm{Al} / \mathrm{Zn}$ ratio of 2.4 at $\% \mathrm{Al}$ was determined by $\mathrm{X}$-ray photoelectron spectroscopy. X-ray diffraction shows a preferential growth in the (0002) $c$-axis direction. Films have an average transparency of $90 \%$ in the visible-light spectrum, a room-temperature resistivity of $3.7 \times 10^{-3} \Omega \mathrm{cm}$ and a carrier mobility of $6.7 \mathrm{~cm}^{2} \mathrm{~V}^{-1} \mathrm{~s}^{-1}$.

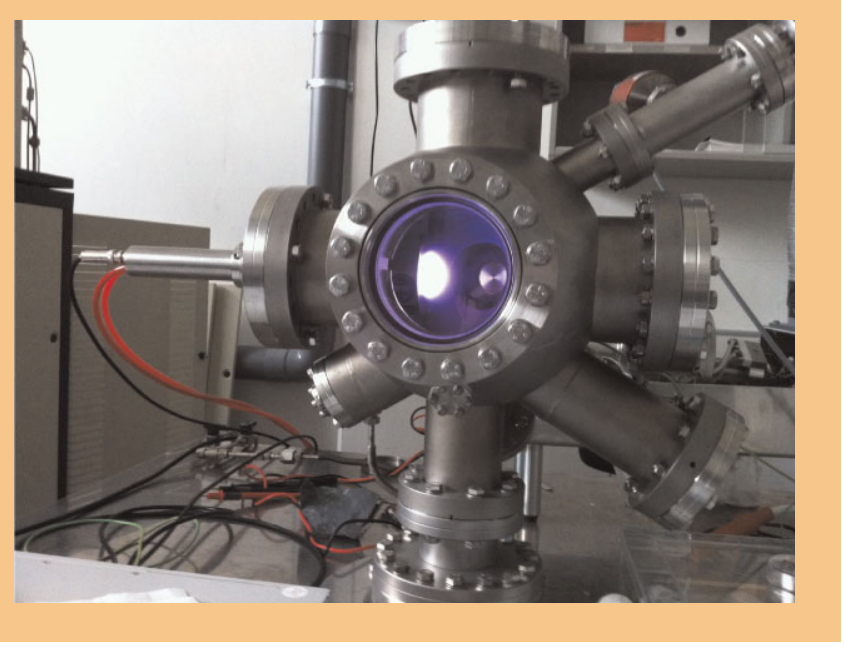

(c) 2013 WILEY-VCH Verlag GmbH \& Co. KGaA, Weinheim
1 Introduction Transparent conductive oxides (TCO) have been known for over 100 years [1] and even today they remain a very active topic of research. TCOs can be described as materials with low resistivity, high mobility, and at the same time have a high transparency for light in the visible wavelength spectrum [2]. Therefore, TCOs are vital materials in the optoelectronic industry with an extensive range of applications. TCOs are used as backing electrode in flat panel displays, energy efficient windows, electroluminescent lamps, and as an electrode for the use in organic, inorganic and/or dye-sensitized solar cells $[3,4]$. Since the fabrication of p-type TCOs presents a major challenge, the majority of TCOs used in industry are n-type semiconductors [5, 6]. Currently, indium tin oxide or tin-doped indium oxide (ITO) is the prevalent n-type TCO used in consumer technology owing to its good optical transmittance and low resistivity as discovered in the 1950s [7]. According to the US Geological survey however, indium is expensive, and recent studies prove that indium is a hazardous material for both environment and humans [8-11]. Replacing ITO with a sustainable and cost effective alternative is therefore inescapable. Because $\mathrm{Zn}$ is an abundant element and is non-toxic when bound in $\mathrm{ZnO}$ [12], doped-zinc oxides are promising to replace ITO. $\mathrm{ZnO}$ is a wide band gap 


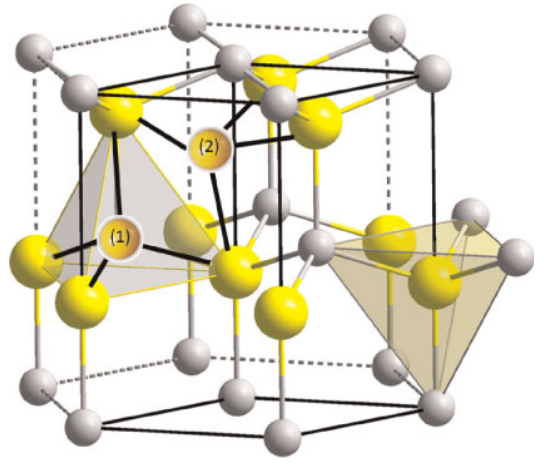

Figure 1 (online color at: www.pss-a.com) Substitution of a $\mathrm{Zn}$ atom by an $\mathrm{Al}$ atom can occur at the tetrahedral position (1). Interstitial doping can occur at the tetrahedral position (2) and octahedral positions [16, 17].

material with n-type semiconducting properties resulting from oxygen vacancies and zinc interstitials. The electrical properties of $\mathrm{ZnO}$ are further enhanced by substituting $\mathrm{Zn}$ with group-III elements such as Al, Ga, and In [13]. From these possibilities, aluminum-doped zinc oxide (AZO) is a very promising candidate because of the low achievable resistivity, high carrier mobility, high stability, and due to the fact that aluminum is less toxic to the environment and less expensive than indium and gallium.

$\mathrm{ZnO}$ can be found in three different crystal forms; cubic rocksalt, cubic zinc blende, and hexagonal wurtzite. The hexagonal crystal structure is thermodynamically the most stable of these three different forms [14]. The lattice constants of hexagonal zinc oxide are $a=0.3249 \mathrm{~nm}$ and $c=0.5207 \mathrm{~nm}$ [15]. The doping mechanism in the hexagonal $\mathrm{ZnO}$ crystal structure of the $\mathrm{Zn}$ atoms by $\mathrm{Al}$ can be substitutional and interstitial, see Fig. 1. Ideally, Al doping is substitutional at the tetrahedral lattice position (1) [16, 17].

Several deposition techniques have been used to deposit $\mathrm{Al}: \mathrm{ZnO}$, including DC- and RF-sputtering [18-20], chemical vapor deposition (CVD) techniques [21], electron beam evaporation [22], cathodic arc deposition [23], sol-gel deposition [24], and laser ablation [25]. Since sputtering deposition, be it RF or DC, is commonly used by the semiconductor industry to deposit thin layers, and because sputtering produces high quality films, this work will focus on reactive DC sputtering in argon-oxygen mixtures. In Table 1, a compendium is given of growth methods and the resulting electrical properties of $\mathrm{Al}: \mathrm{ZnO}$ films.

2 Experimental For the in situ preparation of $\mathrm{Al}: \mathrm{ZnO}$ films, a UHV sputtering system was designed with a base pressure below $10^{-7} \mathrm{hPa}$. The concept of the cathodes was specifically optimized to allow DC sputtering in highpressure atmospheres of several $\mathrm{hPa} \mathrm{O}_{2}$ or $\mathrm{Ar}$ [32]. The system is equipped with two cathodes, which gives the possibility to sputter capping-layers on top of the metaloxide film. The $\mathrm{Al}_{2} \mathrm{O}_{3}$ substrates, Crystec $\mathrm{GmbH}$ (Germany), are cut in the (0001) direction, have a thickness of $1 \mathrm{~mm}$
Table 1 Deposition methods and electric properties of $\mathrm{Al}: \mathrm{ZnO}$ thin films at room temperature.

\begin{tabular}{lllc}
\hline $\begin{array}{l}\text { deposition } \\
\text { method }\end{array}$ & $\begin{array}{l}\rho \\
\left(10^{-4} \Omega \mathrm{cm}\right)\end{array}$ & $\begin{array}{l}N \\
\left(10^{20} \mathrm{~cm}^{-3}\right)\end{array}$ & $\begin{array}{l}\mu \\
\left(\mathrm{cm}^{2} \mathrm{~V} \mathrm{~s}\right)\end{array}$ \\
\hline pulsed DCMRS [26] & 7.33 & 5.84 & 14.6 \\
DCMR S[27] & 4.2 & 2.6 & 57 \\
DCMRS [18] & 18 & 0.19 & 1.8 \\
DC+RFRMS [20] & 5 & 9 & 20 \\
ACMRS [27] & 4 & 4 & 32 \\
RFMRS [28] & 14.3 & 4.25 & 10.3 \\
RFMRS [29] & 2.86 & 7.59 & 30 \\
RFMRS [19] & 3.7 & 4 & \pm 40 \\
RFMRS [30] & 10 & 2.5 & 6 \\
LPCVD [21] & 35 & 3.5 & \pm 5 \\
PLD [25] & 21 & 0.69 & 10 \\
sol-gel [31] & 80 & 40 & 25 \\
\hline
\end{tabular}

$\rho$, resistivity; $N$, majority charge-carrier density; $\mu$, majority charge-carrier mobility. DCMRS, dc magnetron reactive sputtering; RFMRS, rf magnetron reactive sputtering; ACRMS, ac magnetron reactive sputtering; LPCVD, low pressure chemical vapor deposition.

and the size is $10 \times 10 \mathrm{~mm}^{2}$. For deposition, the substrates were glued on resistive heating element with integrated thermocouple, allowing to reach deposition temperature up to $900^{\circ} \mathrm{C}$. To guarantee an efficient heat transfer to the substrate, silver epoxy E-solder 3021 (Epoxy Produkte $\mathrm{GmbH}$, Germany) was applied as a glue between the heater and the substrate. Subsequently, the epoxy was baked at $500{ }^{\circ} \mathrm{C}$ to ensure a homogeneous silver film between the heating element and the substrate. The sputter target was fabricated with Zano-Al nanosized conductive zinc oxide powder containing $1.0 \mathrm{wt} \% \mathrm{Al}$ and was supplied by Umicore (Belgium). Since the atomic weight of $\mathrm{Zn}$ and $\mathrm{Al}$ are 65.41 and $26.98 \mathrm{u}$, respectively, we obtain an atomic $\mathrm{Al}: \mathrm{Zn}$ ratio of $2.4 \mathrm{at} \%$. Portions of $9 \mathrm{~g}$ of this powder were pressed into disks with a diameter of $1.5 \mathrm{inch}$ and a thickness of $\pm 2 \mathrm{~mm}$ by applying an uniaxial pressure of $9.32 \times 10^{5} \mathrm{hPa}$. Afterwards, targets were sintered in a vacuum oven with a base pressure of $5 \times 10^{-7} \mathrm{hPa}$ and $900{ }^{\circ} \mathrm{C}$ for $1 \mathrm{~h}$, resulting in a hard ceramic disk. We note that this temperature is not high enough to incorporate $\mathrm{Al}$ into a $\mathrm{ZnO}$ crystal. However, this is not necessary because the powder is already conductive and sintering is done to obtain a mechanically hard ceramic sputter target. The targets were glued into the water-cooled target holder with silver epoxy resin. Before sputtering, the vacuum chamber was evacuated below $10^{-6} \mathrm{hPa}$. Presputtering of the target, was done at a pressure of $1 \mathrm{hPa} \mathrm{Ar}$ for $1 \mathrm{~h}$. For deposition, the Ar pressure was increased to $2 \mathrm{hPa} \mathrm{Ar}$ and $1 \times 10^{-2} \mathrm{hPa} \mathrm{O}_{2}$ was added to guarantee a sufficient oxidation of the as-deposited films. Sputtering was performed with a power of $36 \mathrm{~W}$ $(80 \mathrm{~mA}, 450 \mathrm{~V})$, resulting in a deposition rate of $45 \mathrm{~nm}$ per hour. As current source for the cathode, a N5752 power supply (Agilent, Germany) was used. The growth time was typically $2 \mathrm{~h}$, corresponding to a estimated film thickness of $90 \mathrm{~nm}$. The low sputter rate is a consequence of the 
absence of a magnetron insert in the sputter cathode, but improves the homogeneity of the film thickness.

XRD measurements were performed with a D5000 diffractometer (Siemens, Germany) in locked-coupled $\theta-2 \theta$ geometry using the $\mathrm{Cu} \mathrm{K} \alpha_{1}$ line $(1.5406 \AA)$. Atomic force microscopy (AFM) was employed in non-contact mode (NCM) to measure the film thickness and the surface roughness using a NX10 AFM instrument (Park Instruments, Korea). A standard pyramidal shaped $\mathrm{Si}_{3} \mathrm{~N}_{4}$ (silicon nitride) cantilever (www.AFMProbe.com) with a length of $125 \mu \mathrm{m}$ and a nominal force constant of $40 \mathrm{Nm}^{-1}$ was used. All measurements were performed in air at room temperature and height, NCM-phase and NCM-amplitude were recorded. The typical scan size was of $45 \times 45 \mu \mathrm{m}^{2}$. X-ray photoelectron spectroscopy (XPS) measurements were performed on a commercial PHI 5600 LS photoemission system (Physical Electronics, Germany) in order to analyze the elemental distribution within the samples. For that purpose, core-level spectra were acquired using monochromatized Al $\mathrm{K} \alpha$ X-rays $\left(1486.60 \mathrm{eV}\right.$, spot size about $1 \mathrm{~mm}^{2}$ ) for photoexcitation. To determine the transparency of the $\mathrm{Al}: \mathrm{ZnO}$ films, $\mathrm{UV}-\mathrm{V}$ is measurements were performed using a CARY 500 spectrophotometer (Agilent, USA).

For the electrical characterization, samples were etched in a Hall-bar pattern (with a length of $0.9 \mathrm{~mm}$ and a width of $0.475 \mathrm{~mm}$ ) by photolithography, using a MJB3 Mask Aligner (Karl Süss, Germany) and microposit S1818 positive resist (Rhom and Haas, USA). The Al: $\mathrm{ZnO}$ thin films were etched with a solution of 1:100 $\mathrm{HNO}_{3}: \mathrm{H}_{2} \mathrm{O}$ for $60 \mathrm{~s}$, and rinsed thoroughly with DI water. Samples were wirebonded with an aluminum wire and fixed into a MicrostatHe cryostat (Oxford instruments, UK) with a temperature range of 4.2 to $400 \mathrm{~K}$. The Hall-effect was measured by placing the cryostate in between a tapered-pole electromagnet (Bruker B-E $15 \mathrm{v}$, Germany) with magnetic field strengths of up to 2.07 T. A 2400 SourceMeter (Keithley, USA) was used in the 4-sense setting to measure the potential used to calculate the resistivity. A second Keithley 2400 SourceMeter was used as a voltmeter to detect the Hall voltage at a magnetic field strength of $2 \mathrm{~T}$ and temperatures ranging from 75 up to $400 \mathrm{~K}$. All resistivity- and Hall measurements were performed with alternating current and field directions to exclude artifacts from thermal voltages and imperfect alignment of the Hall leads. Connections between the cryostat and the electronic instruments were made by shielded coaxial cables.

\section{Results and discussion}

3.1 Sample preparation For the sputtering of $\mathrm{Al}: \mathrm{ZnO}$, different deposition parameters were tested to obtain an optimal result. Pressure, gas mixture, distance between target and substrate, and substrate temperature were varied. The guideline to determine whether the chosen parameters improve film quality, were the optical appearance and sheet resistivity. The preferred optical appearance is a shiny and smooth film as a first indication for crystalline quality. This parameter is relevant in most applications where $\mathrm{Al}: \mathrm{ZnO}$ is used for its good optical transmittance. Second, the sheet resistance was measured with a van der Pauw set-up in order to obtain a first indication for the conductive properties. The optimization of the first two sputter parameters, total pressure and gas mixture, were done simultaneously. The total pressure was varied between $1 \times 10^{-1}$ and $3 \mathrm{hPa}$, above $3 \mathrm{hPa}$, arcing was unavoidable. Especially, sputtering in a pure $\mathrm{O}_{2}$ plasma did not give a stable discharge due to arcing, which occurred already at currents of just $15 \mathrm{~mA}$. The formation of a thin, insulating oxide layer on the ceramic target is a possible explanation. Sputtering in a pure Ar plasma leads to a stable plasma with high currents $(80 \mathrm{~mA})$, but, due to the absence of oxygen, only insulating films could be formed. The optimal mixture between $\mathrm{O}_{2}$ and $\mathrm{Ar}$ was found for $P_{\mathrm{Ar}}=2.0 \mathrm{hPa}$ and $P_{\mathrm{O}_{2}}=1 \times 10^{-2} \mathrm{hPa}$, which corresponds to a $0.5 \% \mathrm{O}_{2}: \mathrm{Ar}$ ratio. Increasing the amount of $\mathrm{O}_{2}$ above $0.5 \%$ leads to an unstable growth process. To remove a possible excess of adsorbed oxygen, resulting in enhanced resistivity values, the films were post-annealed at growth temperature under an Ar pressure of $2.0 \mathrm{hPa}$ for $30 \mathrm{~min}$. In Fig. 2, the resistivity is plotted as a function of the growth temperature. All samples were deposited in the standard atmosphere of the argon-oxygen mixture under continuous gas flow. Films grown at around $400{ }^{\circ} \mathrm{C}$ exhibit the lowest resistivity; deposition temperatures above $500^{\circ} \mathrm{C}$ resulted in opaque films and the optical transmittance diminishes.

3.2 Structural and chemical characterization In Fig. 3, the XRD $2 \theta$-spectrum of an $\mathrm{Al}: \mathrm{ZnO}$ film grown on sapphire is shown. The characteristic $\mathrm{Al}_{2} \mathrm{O}_{3}$ peaks of the substrate at $41.6^{\circ}$ and $90.7^{\circ}$, the (0006) and the (00012) plane, respectively, are clearly visible. The XRD $2 \theta$-spectrum of the $\mathrm{Al}: \mathrm{ZnO}$ thin film with optimal transparency and low resistivity shows the (0002) peak of $c$-axis oriented $\mathrm{ZnO}$ at $34.34^{\circ}$ and the (0004) peak at $72.58^{\circ}$, while no other phases or crystalline orientations are visible. Although the lattice mismatch between $c$-axis sapphire $(a=0.4758 \mathrm{~nm}$ and $c=1.299 \mathrm{~nm})$ and $\mathrm{ZnO}$

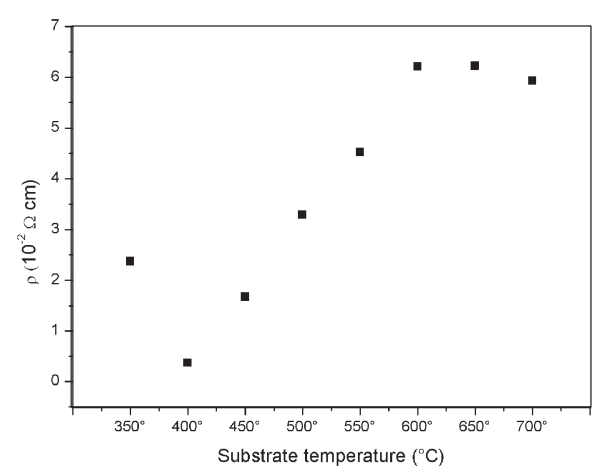

Figure 2 Optimizing the resistivity of $\mathrm{Al}: \mathrm{ZnO}$ films as a function of the growth temperature. All films had a thickness of $90 \mathrm{~nm}$ and were sputtered under $\mathrm{Ar}$ and $\mathrm{O}_{2}$ partial pressures of $2 \mathrm{hPa}$ and $1 \times 10^{-2} \mathrm{hPa}$, respectively. 


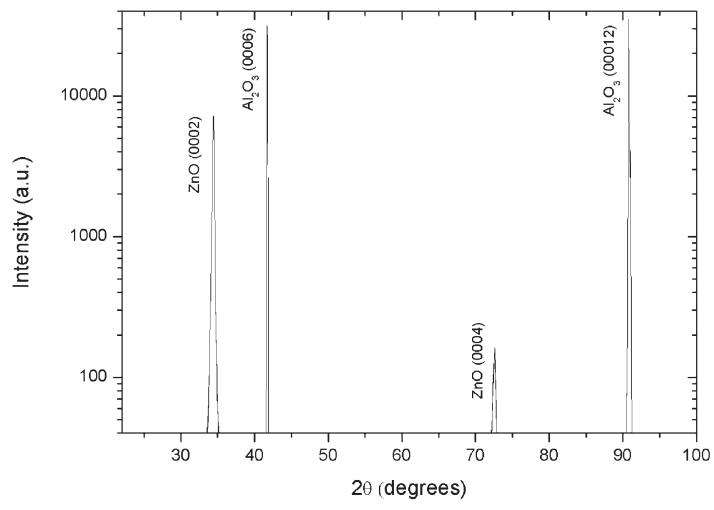

Figure 3 XRD $2 \theta$-spectrum of a $90 \mathrm{~nm}$ thick $\mathrm{Al}: \mathrm{ZnO}$ film deposited at $400{ }^{\circ} \mathrm{C}$ under $\mathrm{Ar}$ and $\mathrm{O}_{2}$ partial pressures of $2 \mathrm{hPa}$ and $1 \times 10^{-2} \mathrm{hPa}$, respectively. The $\mathrm{Al}: \mathrm{ZnO}$ film has a strong $c$-axis orientation while the peaks at $2 \theta=41.6^{\circ}$ and $90.7^{\circ}$ originate from the sapphire substrate.

$(a=0.3249 \mathrm{~nm}$ and $c=0.5207 \mathrm{~nm})$ is large, epitaxial growth of $\mathrm{ZnO}$ on sapphire still seems to be feasible according to literature [33-35]. However, final conclusions on the in-plane orientation of the $\mathrm{ZnO}$ lattice with respect to the underlying substrate cannot yet been drawn.

Figure $4 \mathrm{a}$, reveals that the film is composed of closely packed, wire shaped crystallites. The typical grain size of the crystallites in the substrate plane is $\pm 40 \mathrm{~nm}$. The AFM in Fig. 4b, shows a roughness of approximately $10 \mathrm{~nm}$ (root mean square) for the film while the substrate roughness was $3 \mathrm{~nm}$ (rms), both determined over an area of $45 \times 45 \mu \mathrm{m}^{2}$. This roughness may be attributed to the fact that the film is possibly not completely epitaxial over the entire substrate surface, but grown as a composition of densely packed crystallites with a preferred growth direction along the $c$-axis.

\subsection{Electronic characterization}

3.3.1 XPS Although the ratio of $\mathrm{Al}$ and $\mathrm{Zn}$ atoms in the target is $2.4 \mathrm{at} \% \mathrm{Al} / \mathrm{Zn}$, the ratio of $\mathrm{Al}$ - and $\mathrm{Zn}$-atoms in the films is not known beforehand. This ratio can be measured with XPS using the Shirley algorithm, giving an indication of the overall aluminum content. We note that there are in principle three possible doping sites available as shown in Fig. 1. The XPS spectrum in Fig. 5 is measured at the surface of the $\mathrm{Al}: \mathrm{ZnO}$ film and the information depth is $5 \mathrm{~nm}$. The spectrum shows that the amount of $\mathrm{Al}$ present in the film is equivalent to the $2.4 \mathrm{at} \% \mathrm{Al} / \mathrm{Zn}$ ratio already present in the sputtering target. This way, we can conclude that the stoichiometry of the target and the film are identical within the experimental resolution. No major pollutants or adsorbates were detected in the XPS spectrum.

\subsubsection{Conductivity- and Hall measurements} Resistivity $(\rho)$, mobility $(\mu)$ and the density of charge carriers $(N)$ were measured using a Hall-bar configuration. Both measurements were performed on the same $\mathrm{Al}: \mathrm{ZnO}$

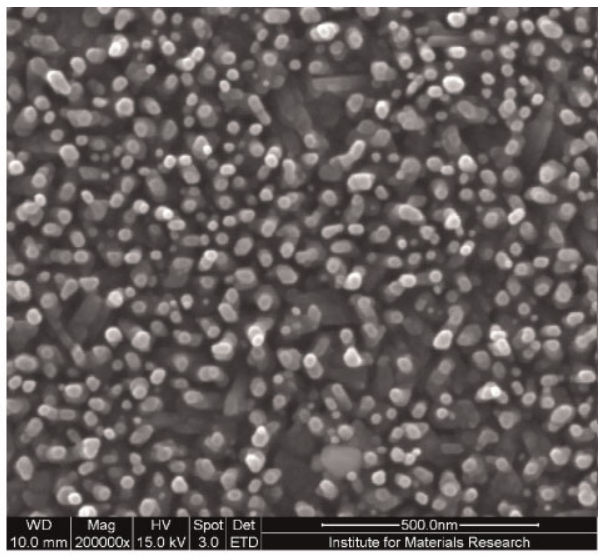

a)

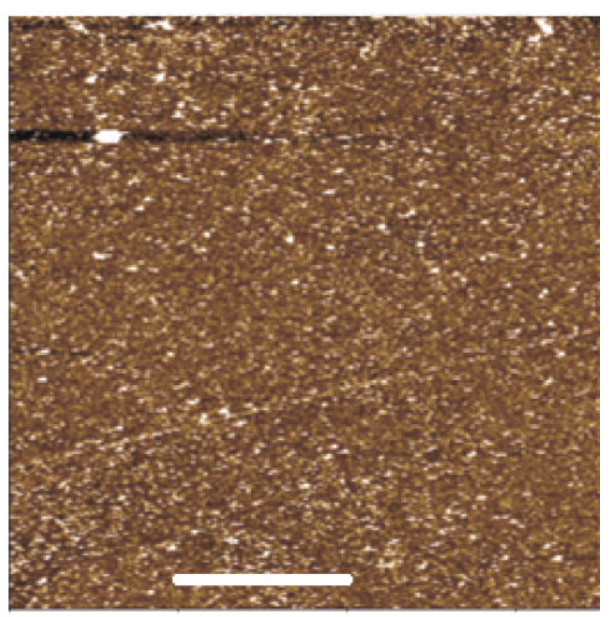

b)

Figure 4 (online color at: www.pss-a.com) (a) SEM and (b) AFM image of an $\mathrm{Al}: \mathrm{ZnO}$ film grown at $400{ }^{\circ} \mathrm{C}$. The scale bar has a length of $10 \mu \mathrm{m}$.

film which was grown at a temperature of $400{ }^{\circ} \mathrm{C}$, at a pressure of $2.0 \mathrm{hPa} \mathrm{Ar}$ and $1.5 \times 10^{-1} \mathrm{hPa} \mathrm{O}_{2}$. The temperature dependence of the resistivity, shown in Fig. 6, indicates a semiconducting behavior. In literature, an

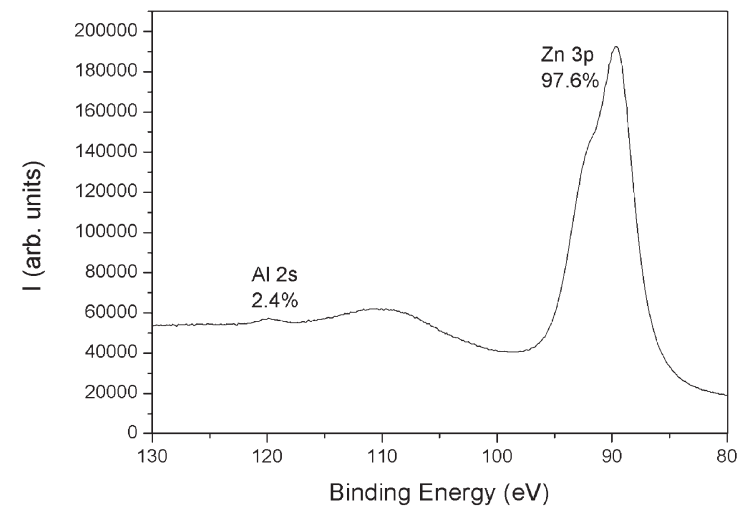

Figure 5 XPS spectrum with the binding energy of the Zn 3p and $\mathrm{Al} 2 \mathrm{~s}$ orbitals. 


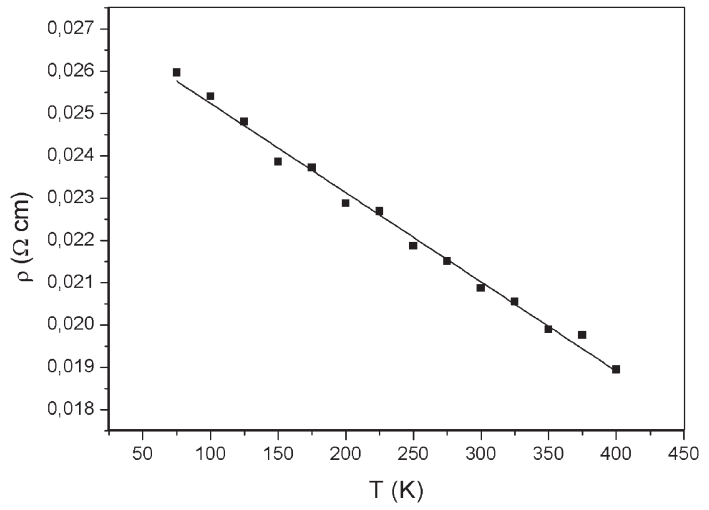

Figure 6 Resistivity measurement on an $\mathrm{Al}: \mathrm{ZnO}$ film grown under optimized sputtering conditions. The solid line is a linear fit with $\rho_{0}=0.027 \Omega \mathrm{cm}, \alpha=2.1 \times 10^{-5} \Omega \mathrm{cm} \mathrm{K}^{-1}$ with an $R^{2}$ value of 0.99 .

Al-doping between $2-3$ at $\%$ is considered as a transition region between metallic behavior $(0.1-2$ at $\%)$ and semiconducting characteristics (3 and up at $\%$ ) [36, 37]. The semiconducting behavior has been attributed to the formation of the aluminum-rich $\mathrm{ZnAl}_{2} \mathrm{O}_{4}$ spinel phase, which in turn also decreases the carrier mobility [38]. However, we point out that there are no indications for the spinel phase in the X-ray spectrum shown in Fig. 3. The temperature dependence of the resistivity was fitted empirically with the equation $\rho(T)=\rho_{0}-\alpha T$. This fit yields $\rho_{0}=0.027 \Omega \mathrm{cm}$ and $\alpha=2.1 \times 10^{-5} \Omega \mathrm{cm} \mathrm{K}^{-1}$ with $R^{2}=0.99252$. Although $\mathrm{Al}: \mathrm{ZnO}$ films with lower resistivity have been achieved (see Table 1), values are comparable to previous work, when taking the high doping level into account [36].

The mobility data and charge-carrier density results are presented in Fig. 7. The mathematical relation $\mu_{n}=\left(N q_{n} \rho\right)^{-1}$ was used to calculate $N$. The number of charge carriers is widely constant within a broad temperature range from 75 to $400 \mathrm{~K}$. This indicates that there are no

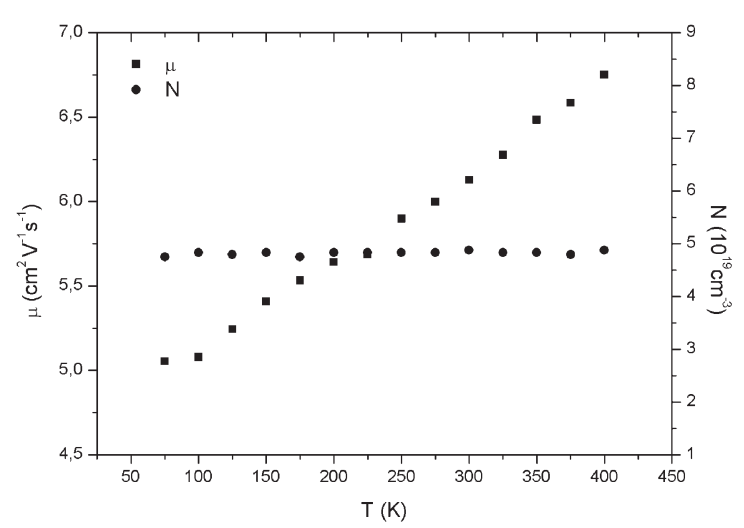

Figure 7 Hall measurement of an $\mathrm{Al}: \mathrm{ZnO}$ film grown under optimal sputtering conditions. The solid squares indicate the mobility (left axis) while the carrier concentration is given by solid dots (right-hand axis). structural- or electronic phase transitions present. The absolute density of carriers is lower than reference values summarized in Table 1: With a doping percentage of $2.4 \mathrm{at} \% \mathrm{Al}$, we estimate the number of $\mathrm{Al}$ atoms to be $9.97 \times 10^{20} \mathrm{~cm}^{-3}$. This number, together with a charge carrier density of $4.8 \times 10^{19} \mathrm{~cm}^{-3}$ yields to a doping efficiency of $4.8 \%$. This low efficiency can be attributed to either the formation of amorphous inclusions or to a trapping of charge carriers at grain boundaries visible in SEM micrograph in Fig. 4a. However, it is noteworthy that the electron mobility of the $\mathrm{Al}: \mathrm{ZnO}$ thin film rises with increasing temperature. According to Matthiessen's rule [39], the mobility is dependent of phonon scattering and impurity scattering. The impact of phonon scattering on the mobility is proportional to temperature, while the contribution of impurity scattering should be temperature independent. Due to the high doping, the effect of phonon scattering is probably too small in comparison to the effect of impurity doping. Therefore, measurements in extended temperature ranges would be needed to distinguish clearly between these possible scattering mechanisms. The highest mobility found with our samples is $6.8 \mathrm{~cm}^{2} \mathrm{~V}^{-1} \mathrm{~s}^{-1}$ at $400 \mathrm{~K}$, being in the same range as literature data for the same doping level (see Table 1). Nevertheless, similar increase of the mobility with increasing temperature has been reported earlier for organic conductors and was explained in a model where charge transport is governed by trapping and thermally-induced release of carriers at localized states in grain boundaries [40].

3.4 Optical characterization Transparency measurements by UV-Vis absorption spectroscopy, see Fig. 8, where done on a $\mathrm{Al}: \mathrm{ZnO}$ film grown on glass. Measurements on films grown on sapphire were not possible due to the unpolished backside of the sapphire substrates. These results reveal a transparency up to $96 \%$ at $430 \mathrm{~nm}$, which is equivalent to the best literature values [41, 42]. This is a promising result for future applications of the sputtered $\mathrm{Al}: \mathrm{ZnO}$ film in devices such as organic LEDs and solar cells.

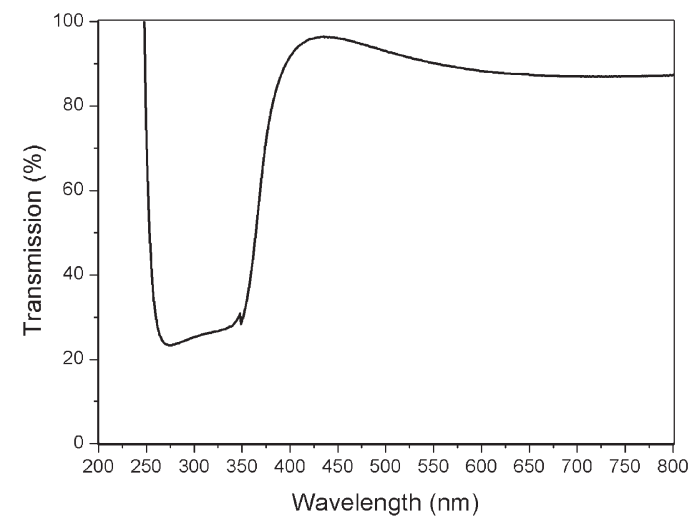

Figure 8 Optical transmission measurement of an $\mathrm{Al}: \mathrm{ZnO}$ thin film with a thickness of $100 \mathrm{~nm}$ grown on glass at $400{ }^{\circ} \mathrm{C}$. 
4 Summary $\mathrm{Al}: \mathrm{ZnO}$ films were prepared by dcsputtering on sapphire substrates without a magnetron or RF power and the electronic properties were studied. Best results were obtained with a substrate temperature of $400{ }^{\circ} \mathrm{C}$ and $2.0 \mathrm{hPa}$ Ar pressure with $1-2 \times 10^{-2} \mathrm{hPa} \mathrm{O}_{2}$ added. The film is composed of densely packed crystallites with a preferential growth along the $c$-axis direction. Although the doping amount of the $\mathrm{Al}: \mathrm{ZnO}$ film is above the known solution limit of $\mathrm{Al}$ in the $\mathrm{ZnO}$ crystal, which can vary from 0.2 to 2 at $\%$ [17], electrical properties are comparable to literature values, with a room-temperature resistivity of $3.7 \times 10^{-3} \Omega \mathrm{cm}$ and a carrier mobility of $6.7 \mathrm{~cm}^{2} \mathrm{~V}^{-1} \mathrm{~s}^{-1}$. Furthermore, the mobility was found to have a thermally activated behavior while the carrier density itself is temperature independent. Regarding the optical transparency in the regime of visible light, the films are close to the state of the art although the proposed deposition process is straight forward and no special annealing steps were applied.

Acknowledgements In this work, we gratefully acknowledge Johnny Baccus and Johan Soogen for all the technical support they have provided with building the sputtering system. Also, Wim Deferme and Jean Manca for providing the equipment for optical measurements, Stoffel Janssens for the fruitful discussions and Bart Ruttens for help with the XRD measurements. Financial support by Hasselt University, the Methusalem network NANO Antwerp - Hasselt, and BELSPO IAP VI is greatly appreciated.

\section{References}

[1] K. Bädeker, Ann. Phys. (Leipzig) 22, 749-766 (1907).

[2] S. Calnan and A. Tiwari, Thin Solid Films 518, 1839-1849 (2010).

[3] C. Granqvist, Sol. Energy Mater. Sol. Cells 91, 1529-1598 (2007).

[4] H. Saarenpää, T. Niemi, A. Tukiainen, H. Lemmentyinen, and N. Tkachenko, Sol. Energy Mater. Sol. Cells 94, 1379 1383 (2010).

[5] U. Özgür, Y. Aliviv, C. Liu, A. Teke, M. Reshchikov, S. dogan, V. Avrutin, S. Cho, and H. Morkoç, J. Appl. Phys. 98, (2005).

[6] J. Lee, N. Subramaniam, J. Lee, S. Kumar, and T. Kang, Europhys. Lett. 95, 47002 (2011).

[7] G. Rupprecht, Z. Phys. 139, 504-517 (1954).

[8] D. Xu, Z. Deng, J. Xiao, C. Liang, Z. Pei, and C. Sun, Phys. Lett. A 346, 148-152 (2005).

[9] A. Tanaka, M. Hirata, Y. Kiyohara, M. Nakano, K. Omae, M. Shiratani, and K. Koga, Thin Solid Films 518, 2934-2936 (2009).

[10] A. Tanaka, M. Hirata, M. Omura, N. Inoue, T. Ueno, T. Homma, and K. Sekizawa, J. Occup. Health 44, 99-102 (2002).

[11] M. Blazka, D. Dixon, E. Haskin, and G. Rosenthal, Fund. Appl. Toxicol. 22, 231-239 (1994).
[12] M. Heinlaan, A. Ivask, I. Blinova, H. C. Dubourguier, and A. Kahru, Chemosphere 71, 1308-1316 (2008).

[13] G. Exarhos and X. Zhou, Thin Solid Films 515, 7025-7052 (2007)

[14] A. Ashrafi, J. Appl. Phys. 102, (2007).

[15] H. McMurdie, M. Morris, E. Evans, B. Paretzkin, W. Wong-Ng, L. Ettinger, and C. Hubbard, Powder Diffr. 1, 76 (1986).

[16] J. Zhang and W. Que, Sol. Energy Mater. Sol. Cells 94, 21812186 (2010).

[17] H. Serier, M. Gaudon, and M. Ménétrier, Solid State Sci. 11, 1192-1197 (2009).

[18] K. Ellmer and R. Wendt, Surf. Coat. Technol. 93, 21-26 (1997).

[19] S. Bose, S. Ray, and A. Barua, J. Phys. D, Appl. Phys. 29, 1873 (1996).

[20] T. Minami, T. Miyata, and Y. Ohtani, Phys. Status Solidi A 9 , 3145-3151 (2007)

[21] J. Nishino, Mater. Res. Soc. Symp. Proc. 363, 219-224 (1995).

[22] D. R. Sahu, S. Y. Lin, and J. L. Huang, Sol. Energy Mater. Sol. Cells 91, 803-813 (2007).

[23] A. Anders, S. Lim, K. Yu, J. Andersson, and J. Rosén, Thin Solid Films 518, 3313-3319 (2010).

[24] K. Schellens, B. Capon, C. De Dobbelaere, C. Detavernier, A. Hardy, and M. K. Van Bael, Thin Solid Films 524, 81-85 (2012).

[25] M. Kumar, R. Mehra, and S. Y. Choi, Curr. Appl. Phys. 9 , 737-741 (2009).

[26] Y. Chen, P. Wang, J. Hsu, and C. Lee, Vacuum 87, 227-231 (2013).

[27] S. Jäger, B. Szyska, J. Szczyrbowski, and G. Bräuer, Surf. Coat. Technol. 98, 1304-1314 (1998).

[28] A. A. Alnajjar, Adv. Condens. Matter Phys. 2012 (2012).

[29] R. Hong, X. Jiang, G. Heide, B. Szyszka, V. Sittinger, and W. Werner, J. Cryst. Growth 249, 461-4469 (2003).

[30] N. Neves, R. Barros, E. Antunes, J. Calado, E. Fortunato, R. Martins, and I. Ferreira, J. Eur. Ceram. Soc. 32, 4381-4391 (2012).

[31] J. P. Lin and J. M. Wu, Appl. Phys. Lett. 92, 134103 (2008).

[32] P. Wagner, H. Adrian, and C. Tomé-Rosa, Physica C 195, 258-262 (1992).

[33] Klingshirn. Phys. Status Solidi B 244, 3027-3073 (2007).

[34] M. Nistor, F. Gherendi, N. Mandache, C. Herbert, J. Pierriere, and W. Seiler, J. Appl. Phys. 106, (2009).

[35] S. Hong, Y. Chen, H. Ko, and T. Yao, Phys. Status Solidi B 229, 803-813

[36] Y. Zhang and W. Wang, Int. J. Appl. Ceram. Technol. 9, 374 381 (2012).

[37] O. Bamiduro, H. Mustafa, R. Mundle, R. Konda, and A. Pradhan, Appl. Phys. Lett. 90, (2007).

[38] K. Cai, E. Müller, C. Drašar, and A. Mrotzek, Mater. Sci. Eng. B 104, 45-48 (2003).

[39] A. Matthiessen and C. Vogt, Philos. Trans. R. Soc. London 154, 167-200 (1864).

[40] G. Horowitz and M. Hajlaoui, Synth. Met. 122, 185-189 (2001).

[41] R. Shukla, A. Srivastava, A. Srivastava, and K. Dubey, J. Cryst. Growth 294, 427-431 (2006).

[42] M. Suchea, S. Christoulakis, N. Katsarakis, T. Kitsopoulos, and G. Kiriakidis, Thin Solid Films 515, 6562-6566 (2007). 